\title{
Um incompreensível esquecimento
}

\author{
Tiago Porteiro
}

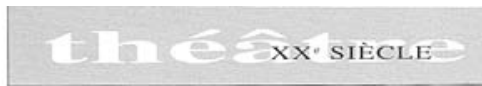

\section{Firmin Gémier}

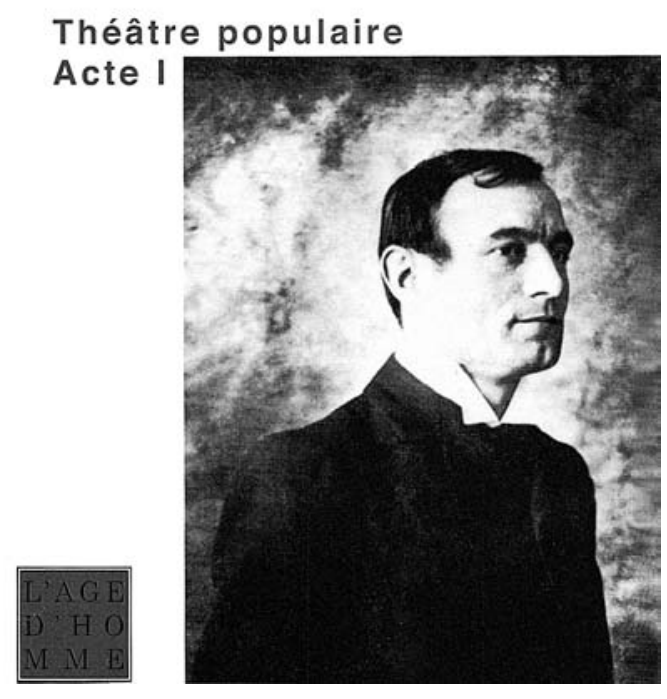

A antologia de textos de Firmin Gémier (1869-1933) que agora se publica - Théâtre populaire:Acte I, (L'Age d'homme, 2006) - uma compilação seleccionada de entrevistas, discursos, conferências e cartas por ele escritos até $1925^{1}$, oferece-nos um panorama abrangente do pensamento e da acção interventiva daquele que foi em França, muito antes de Jean Vilar, o verdadeiro fundador do Théâtre National Populaire. Para os que consideram imprescindivel conhecer a história do teatro impõe-se perguntar: como foi possivel que o seu legado tenha caído num total esquecimento? ${ }^{2}$ Foi efectivamente para preencher esta lacuna que as edições "L'Age d'homme", Th XX - colecção dirigida por Béatrice Picon-Vallin que dá a conhecer práticas fundadoras do teatro do século XX - publicaram estes textos.

Antes de propriamente se apresentar a antologia em questão, importa determo-nos em alguns aspectos do percurso de F. Gémier. Na qualidade de actor, depois de ter representado em diversos teatros da periferia parisiense, integra aos 18 anos o Teatro-Livre de André Antoine. Em seguida, atingindo popularidade e reconhecimento, participa noutros projectos teatrais antes de protagonizar um dos papéis mais emblemáticos da sua carreira: o Pai Ubu, na peça de Ubu Roi, de Alfred Jarry, sob a direcção de Lugné-

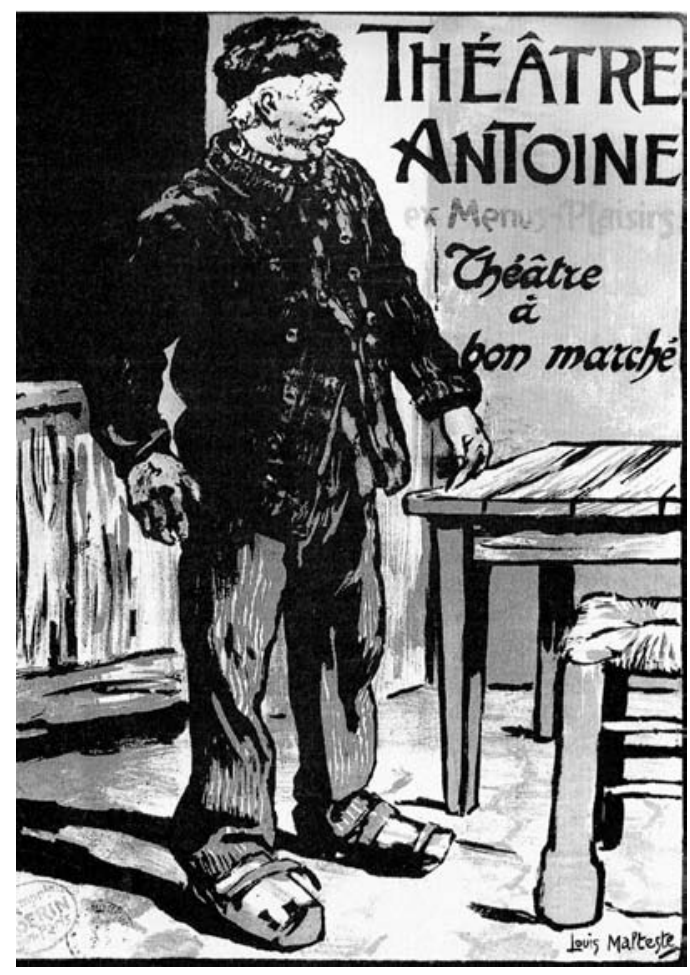

Capa do livro.

é docente da Universidade de Évora.

\section{1. ${ }^{\circ}$ Cartaz do Théâtre Antoine, Setembro de 1897}

Poe. Apesar das várias experiências, foi no trabalho desenvolvido junto de Antoine que ele criou as bases estruturantes da sua visão da profissão. Depois de um percurso significativo enquanto actor, Gémier decide investir no campo da encenação, ao mesmo tempo que, em diferentes teatros, assume funções de direcção: o Théâtre Gymnase, o Théâtre de la Renaissance, o Théâtre Antoine e o Odéon foram, entre outros, aqueles em que a sua acção foi mais significativa. Por entre os projectos directamente fundados por Gémier destaca-se a criação do Théâtre National Ambulant (1911-1912) e do Théâtre National Populaire (1920-1935). Enquanto o primeiro surge como resultado de uma reflexão que define a necessidade de ir ao encontro do público para Ihes apresentar um teatro acessivel, o segundo, que ele dirige até ao final da sua vida, é o que vem consubstanciar a sua visão.

A estes dados biográficos juntem-se agora alguns dados contextuais. Entre os finais do século XIX e o início do século $X X$, paralelamente às grandes transformações sócio-culturais ocorridas, vive-se um periodo de grandes reformas e inovação no teatro. 0 surgimento de uma nova figura, o encenador, vem alterar todo o edifício da criação. 0 campo agora aberto faz emergir novos debates e incita à procura de novos caminhos. Do ponto de vista estético
'Esta publicação é o resultado de um trabalho de investigação mais amplo desenvolvido por Catherine Faivre-Zellner. A mesma autora já publicou o livro Firmin Gémier, Héraut du théâtre populaire, Presses

Universitaires de Rennes, 2006, 340 pp. É por esse facto que a antologia agora apresentada tem a designação de Acte I. entrevistas reunidas por Paul Gsell (Paris, edições Grasset, 1925) era, até à presente data, a única obra editada que expunha a sua visão do teatro "Popular".
${ }^{2}$ Le théâtre, conjunto de 
assiste-se, por exemplo, a um confronto entre visões divergentes: de um lado os naturalistas, tal como A. Antoine; do outro os simbolistas, como é o caso de Lugné-Poe. É neste terreno, efervescente e repleto de interrogações, que Firmin Gémier desenha a especificidade da sua reflexão: em primeiro lugar o que o preocupa não são os aspectos artísticos ligados à renovação interna da cena, mas sim o olhar para esta actividade a partir do ângulo da recepção. Embora estas duas perspectivas não se excluam mutuamente, aquilo em que Gémier é efectivamente precursor, e que esta antologia procura salientar, é a forma como concebe a função do teatro: um dos meios mais eficazes de unir e educar o povo, sem exclusões sociais. É a partir deste pressuposto que ele estrutura e desenvolve todo o seu pensamento e acção. Importa referir que o ângulo de interrogação por ele escolhido não lhe é exclusivo. Por exemplo, constituiram grandes referências para a sua prática as experiências anteriores, quer de Maurice Pottecher (com a criação do "Théâtre du Peuple de Bussang" (1895) no espaço da sua fábrica, onde amadores e operários experimentavam e assistiam às representações), quer de Louis Lumet (criação de um teatro ambulante, o "Théâtre Civique" (1897)). Do ponto de vista teórico destaca-se igualmente como referência a obra de Romain Rolland intitulada Théâtre du peuple (1913). Em suma, estes diferentes intervenientes da cena francesa corporizam uma das correntes em voga nessa época: a criação de um teatro popular com um pendor fortemente político e social. É, em seguida, o terreno do pós-guerra que vai favorecer o surgimento de um teatro popular instituído. Não se pode deixar de assinalar que esta perspectiva de um teatro "popular", capaz de educar e de melhorar o povo, se insere no espírito do tempo, que, por sua vez, estabelecia fortes laços de familiaridade com os valores defendidos pela Revolução Francesa.

Feita esta contextualização, detenhamo-nos na organização e nos conteúdos da antologia de textos.

No prefácio da compilação Jean-Pierre Sarrazac situa desde logo, a relação que o "herdeiro" de Antoine estabelece com o acto da escrita: Gémier não escreveu teoria nem tão pouco romances, mas, pontualmente, reflexões e tomadas de posição que ora anunciavam ora fundamentavam as suas intervenções práticas. Catherine Faivre-Zellner, depois de assinar a introdução onde contextualiza a obra de F. Gémier, apresenta e resume cada texto publicado. Nos diferentes textos que se seguem podemos encontrar, de forma diversificada, reflexões sobre os fundamentos e os objectivos dos projectos realizados, proposições militantes em favor de um teatro "popular", exposições comentadas das suas referências históricas e estéticas, descrições detalhadas sobre encenações efectuadas e também algumas das suas interrogações pedagógicas. Estes documentos, que dão conta das tentativas, das conquistas e também dos fracassos de Gémier, têm como referência organizativa as etapas mais significativas do seu percurso: "Du théâtre de la Renaissance au Théâtre Antoine", "Le Théâtre National Ambulant Gémier", "Le Grand Will et les trois arts frères", "Le théâtre de la foule", "Le Théâtre populaire, nouveau théâtre d'art", Le Théâtre National Populaire", "De vieux camarades", e "L'Internationale au théâtre".

Como anteriormente referenciado, embora os diferentes documentos abordem, do ponto de vista dos conteúdos, domínios diversificados, um denominador comum pode ser identificado: o discurso de um homem que visa instaurar, de forma persistente, um teatro "popular". Na verdade, elevar o lugar e o sentido do teatro na sociedade onde vivia tornou-se a missão da sua vida.

Dado que a denominação "popular" é susceptivel de leituras várias, importa agora caracterizar os pilares da sua perspectiva que nestes textos podemos encontrar. Teatro "popular" foi, antes de mais, um conceito que Gémier circunscreveu em oposição ao de teatro "burguês", um teatro que se criava unicamente para servir uma elite, para proclamar os seus valores egocêntricos e egoístas. Por esse facto, F. Gémier afirmava, vezes sem conta, que a "distância entre a arte e o povo deve deixar de existir" (p. 84). Tal como Antoine, Gémier defendia que o teatro deve, pelo contrário, ter uma dimensão civica de "educação das massas", deve ser "um utensilio de intervenção social", um instrumento ao serviço de um ideal político igualitário. $\mathrm{Na}$ verdade, o projecto de refundação do teatro que Gémier tentou edificar implicava a necessidade de chamar a si temas e formas que respondiam a uma nova visão da sociedade. Os modelos para edificar o seu projecto seriam: as origens do teatro da Grécia antiga, as festas e os actos pastorais da Idade Média, Shakespeare e Molière. Em resumo, era para ele indispensável revisitar as referências estruturantes do teatro para que este se tornasse "novo" no sentido de poder inscrever-se numa perspectiva pedagógica enquanto festa popular que procura federar sem nivelar, uma festa colectiva do verbo, da música e do gesto, de modo a voltar a ser um agente para desenvolver a fraternidade entre homens.

Identifiquemos, por último, os aspectos que esta compilação expõe e que nos ajudam a caracterizar a dimensão estética deste teatro "popular", divertido e comovente, e, nesse sentido, acessivel a todos. Com efeito, Gémier defendia que a base estruturante do teatro assentava na qualidade literária do texto dramático, e isto apesar de 

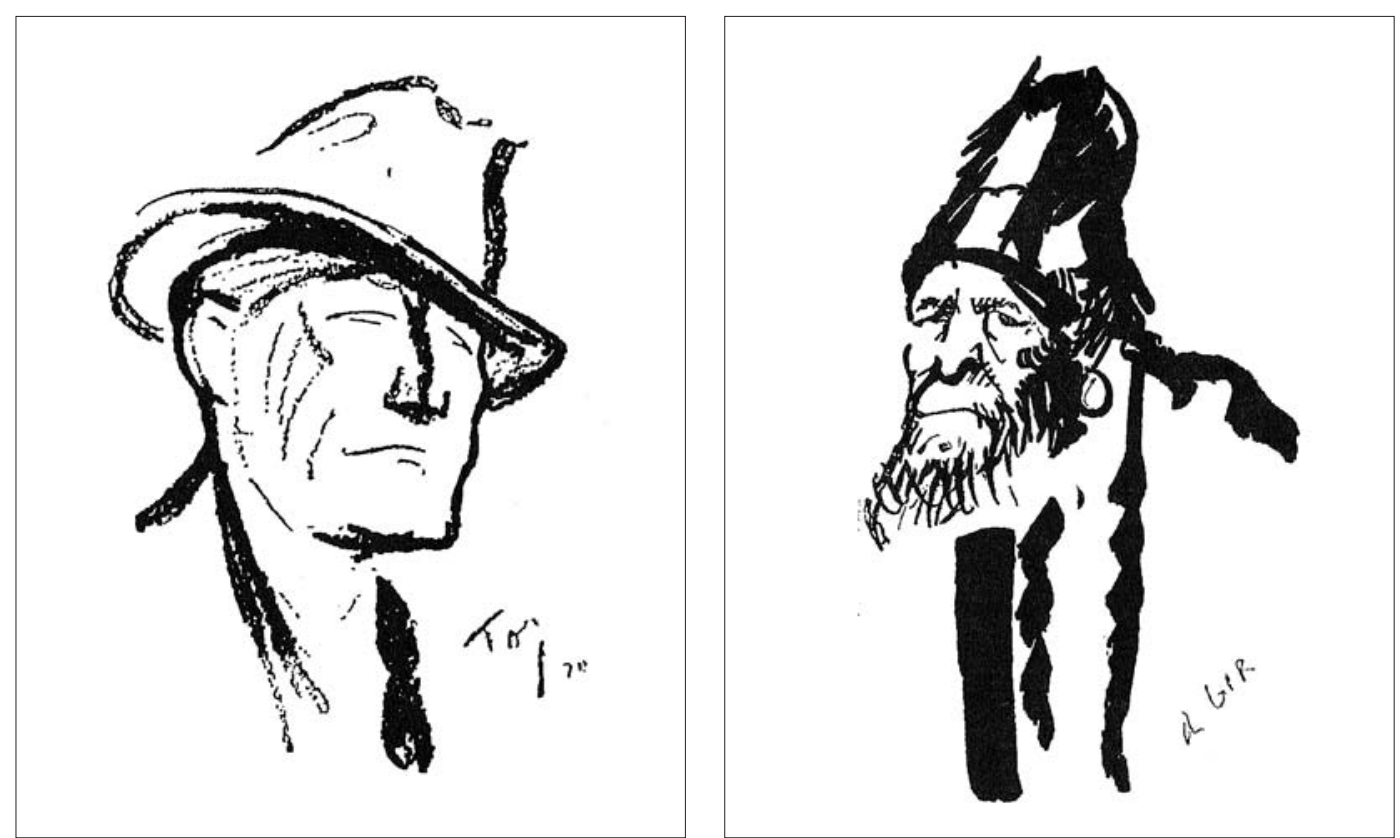

Gémier: desenho de Tor

(Comedia,

11 de Setembro de 1922).

Gémier no papel de Shylock, desenho de Gir (Comedia,

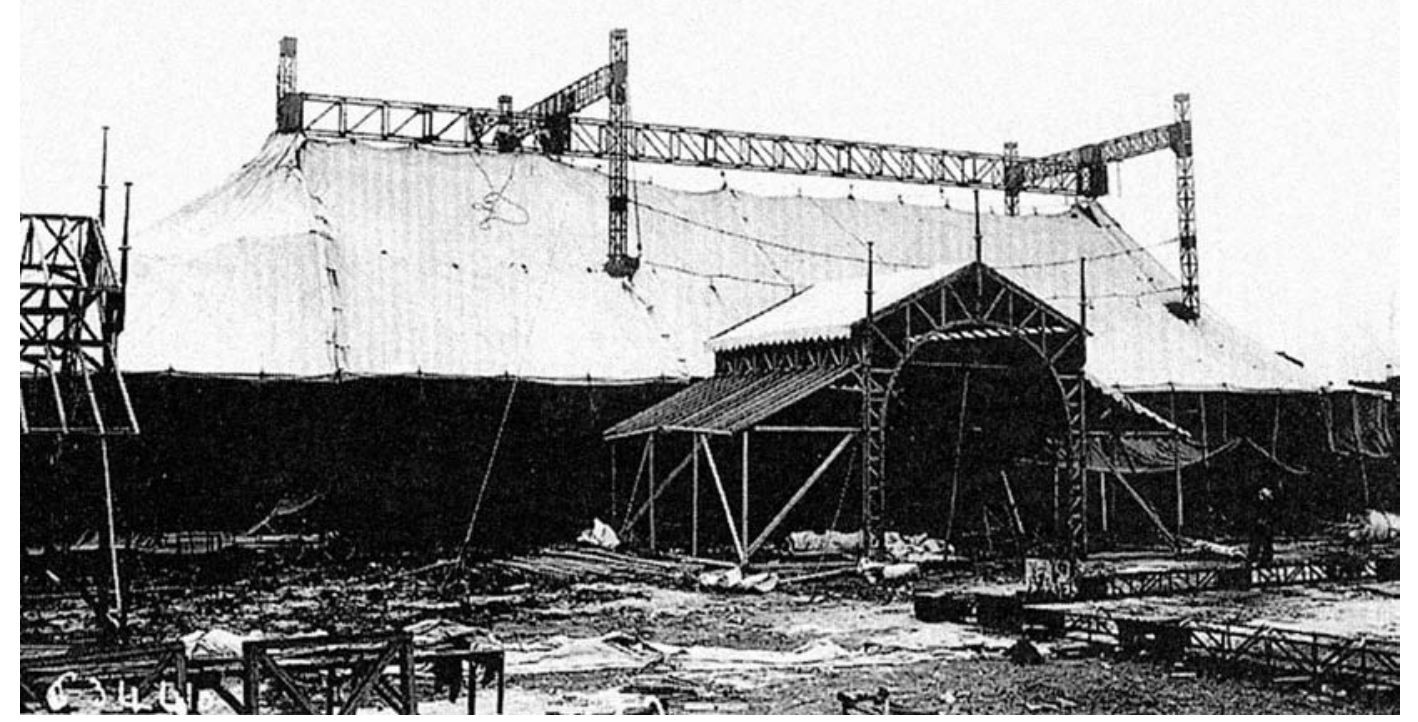

considerar que as "palavras têm muito valor", mas que elas se "devem subordinar à acção cénica" (p. 72). Considerava também que o papel do encenador consiste, antes de mais, em "respeitar as intenções do autor" e de "traduzir esse espírito da obra a cada um dos intérpretes" (p. 79). Os textos apresentados mostram-nos ainda que o acto teatral que procurou fundar se alicerçava no trabalho de um actor eticamente responsável. Esse projecto só se podia desenvolver no seio de um colectivo, o que quer dizer que nele não existia espaço para que o "estrelato" de alguns em detrimento de outros. No entanto, dizer que a sua proposta assenta no trabalho do actor não implica considerar que ele não tenha dado relevância às questões do espaço cénico e da cenografia. Nestes domínios, o despojamento e um contacto próximo com o público foram sempre princípio que pautaram a sua pesquisa. Por fim, podemos acrescentar o princípio segundo o qual Gémier considerava que o seu teatro não podia estar dependente de uma lógica comercial e, portanto, caberia ao poder público assegurar a sua viabilidade.

Será que as propostas de Firmin Gémier terão ainda algum eco hoje?

Ao reler estas páginas fica-nos a sensação que nas suas interrogações e nas suas respostas podemos ainda encontrar, de forma bem evidente, um modelo susceptível de actualização.

A terminar, não podemos deixar de lembrar um alerta de Firmin Gémier: "Repito-vos: sou um pouco quimérico. As minhas perspectivas estão para além de todas as muralhas" (p. 64).

Firmin Gémier, anti-conformista, visionário que idealiza para além do seu tempo incita-nos a inventar o futuro. Veja-se, por exemplo, a sua proposta, já em 1921, de criar uma "Société Universel du théâtre", uma plataforma de artistas capazes de intervirem e de desenvolverem, em conjunto, projectos comuns de reflexão, criação e difusão É por isso que a voz e as crenças que nos deixou em herança têm ainda muito para nos ensinar. 